\title{
Polos hegemónicos y construcción de identidades: una articulación arquitectónica para la conformación de un modelo de democracia entre la pasión y la racionalidad ${ }^{*}$
}

\author{
Marcela Díaz Osorio \\ Edisson Leonardo Parra Herrera****
}

Recibido: 4 de abril de 2016 - Aprobado: 6 de mayo de 2016

$\mathbf{R}$

Este artículo propone una estructura arquitectónica para una democracia alterna, conjugando lógicas de la razón y de la pasión. La estructura parte de la ontología del poder, de la intersubjetividad y de la conflictividad humana como suelo de la construcción de identidades políticas que denominamos polos hegemónicos; esto, como reacción a la despolitización del espacio público. La arquitectura al interior de los polos, sus fronteras políticas y la interacción entre ellos develan una ciudadanía capaz de una pluralidad multidimensional. Esta arquitectura toma como materia prima dos modelos de democracia supuestamente antitéticos, que se proclaman como alternativa a formas de democracia centradas en las élites: el modelo democrático de Jürgen Habermas y el modelo agonista de Chantal Mouffe.

Palabras clave: democracia, ética discursiva, agonismo, espacio público, polos hegemónicos.

Artículo de reflexión. Este texto surge de una investigación sobre democracia, adelantada en el marco del seminario Filosofía de la Educación, realizado en la Universidad de los Andes en el primer semestre de 2014. Agradecemos al profesor Andrés Mejía, quien dirigió el seminario. Una versión preliminar de esta investigación fue presentada en el III Congreso de enseñanza de la ética: ciudadanía, disenso y paz, en 2015 en la Pontificia Universidad Javeriana. DOI: http://dx.doi.org/10.15332/s0120-8454.2016.0089.02

* Magíster en Educación de la Universidad de los Andes. Profesora de Matemáticas en la Facultad de Ciencias Naturales y Matemáticas de la Universidad del Rosario y de la Universidad Jorge Tadeo Lozano. Dirección postal: 111711 Correo electrónico: m.diaz11@uniandes.edu.co,marcejour@yahoo.com.

*** Estudiante del Doctorado en Educación de la Universidad de los Andes. Magíster en Filosofía de la Pontificia Universidad Javeriana. Licenciado en Educación Básica con Énfasis en Ciencias Sociales de la Universidad Pedagógica Nacional. Actualmente es coordinador de convivencia en el Colegio San Agustín IED. Dirección postal: Correo electrónico: el.parra10@uniandes.edu.co. 


\title{
Hegemonic poles and building of identities: An architectural articulation for the creation of a model of democracy between passion and rationality*
}

\author{
Marcela Díaz Osorio* \\ Edisson Leonardo Parra Herrera***
}

\section{Abstract}

This paper proposes an architectural framework for a democratic alternative combining logic of reason and passion. The structure of the ontology of power, intersubjectivity and human conflict is the floor building structure that we call hegemonic poles. These poles are political identities. The architecture inside the poles, political boundaries and the interaction between them reveal a citizenry capable of multidimensional plurality. As feedstock, this architecture takes two antithetical models of democracy, which are proclaimed as alternative forms of democracy centered in elites: the democratic model of Habermas and Mouffe agonist model.

Keywords: Democracy, agonism, ethic discourse, public space, hegemonic poles.

Reflection paper. This text is the result of a research on democracy, conducted in the seminar of Philosophy of Education from Universidad de los Andes, during the first semester of 2014. We would like to thank Professor Andres Mejia, leader of the seminar. A preliminary version of this research was presented at the III Congress of Ethics Education: citizenship, dissent and peace, in 2015 at Pontificia Universidad Javeriana. DOI: http://dx.doi.org/10.15332/s0120-8454.2016.0089.02

** Master in Education from Universidad de los Andes. Professor of Mathematics at the Faculty of Natural Sciences and Mathematics of Universidad del Rosario and Universidad Jorge Tadeo Lozano. Postal Code: 111711. Email: m.diaz11@ uniandes.edu.co, marcejour@yahoo.com.

** PhD student in Education at Universidad de los Andes. Master in Philosophy from Pontificia Universidad Javeriana. Degree in Basic Education with Emphasis on Social Sciences from Universidad Pedagogica Nacional. Current coordinator of coexistence in IED Colegio San Agustin. Email: el.parra10@uniandes.edu.co 


\title{
Pôles hégémoniques et construction d'identités: une articulation architectonique pour la formation d'un modèle de démocratie entre la passion et la rationalité ${ }^{*}$
}

\author{
Marcela Díaz Osorio** \\ Edisson Leonardo Parra Herrera***
}

\section{Résumé}

Cet article propose une structure architectonique pour une démocratie alternative, en conjuguant les logiques de la raison et de la passion. La structure part de l'ontologie du pouvoir, de l'intersubjectivité et des conflits humains comme base pour la construction d'identités politiques que nous appelons pôles hégémoniques; cela, comme réaction à la dépolitisation de l'espace public. L'architecture à l'intérieur des pôles, ses frontières politiques et l'interaction entre eux dévoilent une citoyenneté capable d'une pluralité multidimensionnelle. Cette architecture prend comme matière première deux modèles de démocratie supposées être antithétiques, qui se proclament comme une alternative aux formes de démocratie centrées sur les élites: le modèle démocratique de Jürgen Habermas et le modèle agonistique de Chantal Mouffe.

Mots clés: Démocratie, éthique discursive, agonistique, espace public, pôles hégémoniques.

Article de réflexion. Ce texte surgit d'une recherche sur la démocratie, commencée dans le cadre du séminaire Philosophie de l'Éducation, réalisé à l'Université des Andes durant le premier semestre de 2014. Nous remercions le professer Andrés Mejía, qui a dirigé le séminaire. Une version préliminaire de cette recherche fût présentée pendant le III Congrès de l'enseignement de l'éthique: citoyenneté, dissentiment et paix, en 2015 à I'Université Javeriana. DOI: http://dx.doi.org/10.15332/s0120-8454.2016.0089.02

* Magister en Éducation de l'Université des Andes. Professeur de Mathématiques à la Faculté de Sciences Naturelles et Mathématiques de l'Université Del Rosario et de l'Université Jorge Tadeo Lozano. Adresse postale: 111711. E-mail: m.diaz11@uniandes.edu.co, marcejour@yahoo.com.

.** Étudiante du Doctorat en Éducation de l' Université des Andes. Magister en Philosophie de I'Université Javeriana. Licencié en Éducation Basique avec Spécialité en Sciences Sociales de I'Université Pédagogique Nationale. Actuellement, il est coordinateur de cohabitation à l'École San Agustín IED. Adresse postale: E-mail: el.parra10@uniandes.edu.co. 
Porque el verdadero poder político [...] entraña la capacidad de recibir poder, sufrir influencias, cambiar y ser cambiado. Desde una perspectiva

democrática, el poder no es simplemente una fuerza que se genera, es experiencia, sensibilidad, sabiduría y hasta melancolía, destiladas de las diversas relaciones y círculos en que nos movemos.

Sheldon Wolin

Preocupados, mas no desconsolados, permanecemos un momento al margen, como hombres contemplativos a quienes les está permitido ser testigos de esas luchas y transiciones enormes. ¡Ay! ¡La magia de esas luchas consiste en que quien las mira tiene también que intervenir en ellas!

Friedrich Nietzsche

\section{Introducción}

Quisimos iniciar este escrito con dos epígrafes que sugieren una idea de democracia cercana a las emociones, a lo tangible. También una comprensión del poder político como apertura a los otros, que armonice a los participantes, quienes se permiten "sufrir influencias, cambiar y ser cambiados" (Wolin, año). Para ello quizá resulte necesario ceder y hasta abrazar los argumentos ajenos cuando nos interpelan. Abordaremos igualmente el poder en su tradicional perspectiva de dominio, de lucha. En líneas muy generales, la democracia supone la participación igualitaria de todos, porque no privilegia maneras particulares de relacionarse con otros. Precisamente, las perspectivas democráticas, que son materia prima de nuestra propuesta, configuran el Zeitgeist ${ }^{1}$ político europeo. Bajo dichas perspectivas, el poder se configura ya sea priorizando la razón, ya sea apelando a la dimensión pasional de la política, considerada como ámbito de lucha. Así, en la búsqueda por la democracia, resulta natural preguntarse: ¿por qué no pensar en una pluralidad de pluralidades?, ¿no será que la primacía de la razón o de lo afectivo al interior de la democracia enmascara ciertas intuiciones?

La propuesta esencial de este ensayo es conjugar dos modelos de democracia, que se reconocen como antitéticos, en un intento por proponer una ciudadanía que pueda ser ejercida desde una pluralidad multidimensional. El primer modelo se inscribe en el enfoque de la ética del discurso, la democracia deliberativa de Jürgen Habermas, que busca ser emancipatoria frente a la racionalidad instrumental. El segundo proclama ser una crítica radical frente a este, la democracia pluralista de Chantal Mouffe. Esta tentativa por conjugar ambos modelos no es nueva; Fraser (2008), por ejemplo, no los asume como antitéticos, pues considera que uno y otro descansan en intuiciones complementarias para combatir la complejidad de las injusticias en el tiempo actual. Ahora, si bien

Clima intelectual y cultural de una época. 
en Fraser aparece la idea de no dejar de lado ninguno de los modelos, no es claro de qué forma se constituyen las colectividades o cómo está organizado el espacio político.

La propuesta aquí es conceptualizar esta pluralidad con miras a la construcción de una arquitectónica para la democracia, con ciertos alcances teóricos. En primer lugar, esta hace posible reconocer estas dos dimensiones para superar ciertas patologías de la modernidad, entre ellas, el imperio de la racionalidad instrumental, que margina a los seres humanos a la lógica de la técnica y del mercado, como también el apoderamiento de las corporaciones y multinacionales del ámbito de la política. En segundo lugar, pone de manifiesto que tanto un modelo como el otro pueden dejar perspectivas ocultas cuando se consideran por separado. En particular, es natural considerar que los ciudadanos actúan políticamente, tanto desde lo racional como desde lo afectivo.

Para empezar, en el modelo habermasiano la formación de la voluntad política se basa en una racionalidad comunicativa orientada al entendimiento, en la que los participantes, mediante una ética procedimental, esperan llegar a acuerdos consensuales. Mouffe (2011) afirma que la deliberación comunicativa racional - aun cuando pretenda estar orientada al entendimiento- no siempre deriva en un consenso sin exclusiones. Según su juicio, resulta imposible aunar posiciones ideológicas claramente diferenciadas. Además, el modelo deliberativo podría implicar la homogenización y globalización a ultranza de los seres humanos. Sin embargo, no es válido decir que Mouffe desconoce la posibilidad del consenso; a lo que se opone es a que este sea el fin último de la democracia. En efecto, el obstáculo para la realización del consenso ideal - tal como lo entiende la democracia deliberativa - está inscrito en la misma lógica de la democracia, pues esta no puede existir sin la contraposición nosotros/ellos.

Si reconocemos la naturaleza ambivalente del ser humano, en la que la reciprocidad, pero a la vez el antagonismo están presentes, resulta plausible articular esta doble naturaleza en un modelo complejo de democracia que a la vez sea una arquitectura. Dicha arquitectura engrana la democracia deliberativa de Habermas con el modelo agonista de Mouffe. El eje articulador de la propuesta será la construcción de identidades colectivas en el ámbito político, a partir del análisis propositivo de las dos teorías. Filosóficamente se parte de la ontología del poder propuesta por Mouffe (2011), para mostrar su inmanencia en las distintas construcciones de la política. Así, con el sustento de un enfoque agonista, se dirige la mirada al ámbito del discurso racional, para hallar puntos de entrelazamiento y disolución entre la pasión y la racionalidad discursiva en el escenario de construcción de identidades.

Es importante señalar la "transversalidad" de la ética con relación a las múltiples identidades que confluyen en el espacio de construcción política. ¿Qué y cómo se produce la cohesión en el ámbito de la construcción de identidades colectivas?, ¿cómo repolitizar los espacios públicos sin comprender las formas de producción de las identidades colectivas? En relación con estas preguntas, 
es necesario tener en cuenta las condiciones efectivas de la política referidas a la modernidad y a la posmodernidad, relacionadas con la transición de una razón centrada en el sujeto cognoscente a una intersubjetiva. En este escenario, ¿qué pasa con el espacio público y la construcción de identidades colectivas e individuales que surgen en él?, ¿cómo construir un modelo político en medio de este mundo movible e inestable?

\section{La muerte de la política}

La intención de conjugar dos modelos políticos en uno alterno - cuyos autores son contradictores - parte de la insuficiencia de cada uno por separado. Lo anterior no quiere decir que exista un modelo perfecto que organice de manera armoniosa las relaciones políticas en la sociedad. Con esta reflexión, se pretende entonces encontrar supuestos que permitan potenciar el ámbito de la política. De ahí que sea necesario identificar cuáles son los elementos constitutivos de la política y cómo estos se organizan para dar origen a formas de organización del convivir político. Es así que la superficie de la política no podría comprenderse, si no se dirige la mirada al elemento que la potencia: lo político, asumido como la dimensión del antagonismo, de la lucha y no del entendimiento. Una comprensión real de lo político es quizá un camino para hacer frente a posturas dominantes que, aún con buenas intenciones, podrían ser el terreno fértil para propiciar prácticas hegemónicas globalizadoras. Pensar un modelo político nos remite de inmediato a la pregunta por la validez de la democracia, pues es la forma ideal de organización política contemporánea.

Actualmente, algunos paradigmas de la teoría política concuerdan con el diagnóstico referido a la política: la política ha muerto; sin embargo, al realizar la autopsia del cuerpo, se encuentran diferencias en cuanto a cuáles fueron las causas de la muerte. Para algunos, como Habermas (1998), la política muere cuando las grandes multinacionales se apropian del Estado y, en general, del espacio público. Para otros, como Mouffe (2011), la muerte es ocasionada cuando se adopta el consenso racional como posibilidad de solución de todos los conflictos en el espacio público, por medio de discusiones racionales, negando lo político de la política. Esto implica también una naturalización de las relaciones hegemónicas, que niega cualquier posibilidad de alterar las actuales relaciones de poder.

Ahora, si tenemos en cuenta que una característica de la modernidad es la construcción de espacios públicos o políticos, en los cuáles la sociedad civil ejerce procesos autónomos en relación con el Estado, podemos observar que para lograr la participación de los ciudadanos en la construcción política fue indispensable crear una identidad de estos con una Nación, la cual estaba adscrita a un territorio y administrada por un Estado. Fue entonces en el marco de la construcción de los Estados nación que comienzan a constituirse identidades políticas. 
De esta manera, en cuanto al primer dictamen se evidencia que, con el avance del capitalismo, dichos espacios son absorbidos por la lógica del mercado, el Estado neoliberal valida la racionalidad instrumental o económica al interior del espacio público produciendo la muerte de la política. Así, para Márquez y Díaz (2006), con base en Habermas, la política deja de ser mediada por el logos y pierde su origen dialógico y comunicativo. En suma, la superfetación de la razón instrumental produce la muerte de la política al permear "la política como espacio de interacción ciudadana y como ejercicio de construcción del espacio público" (p. 161).

En medio de esta visión pesimista, Horkheimer, filósofo de la primera escuela de Fráncfort, señala con respecto a la confianza en el progreso tecnocientífico: "los avances en el ámbito de los medios técnicos se ven acompañados de un proceso de deshumanización. El progreso amenaza con destruir el objetivo que estaba llamado a realizar: la idea de hombre" (2002, p. 43). Frente a este diagnóstico, Habermas (1999) instaura la razón comunicativa como alternativa emancipadora frente a la razón instrumental.

El segundo dictamen de la autopsia ha sido denominado por Mouffe (2000) como la visión "pospolítica", en el que se supera el carácter antagónico de la política para dar paso a un sentimiento de unidad logrado mediante debates racionales. En el caso del liberalismo, por ejemplo, la voluntad política de los ciudadanos se moviliza dentro de la racionalidad económica, siendo su principal error creer en un consenso racional que ponga fin a los problemas sociales, pues esto implica la instauración de un único centro de poder. Es así, que al haber superado las identidades colectivas, se abre un espacio de plenitud para las libertades individuales y se acaban los conflictos sociales. De acuerdo con la autora, esta visión es la causa de que las instituciones democráticas se encuentren en una profunda crisis. Mouffe (2011) es contraria a las teorías que, como consecuencia de los avances del desarrollo económico-político y de la globalización de la democracia liberal, ven el advenimiento de un futuro cosmopolita de total armonía y desarrollo pleno de los derechos humanos. Su crítica contra el liberalismo, la democracia deliberativa de Habermas y el modelo agregativo de democracia se centra precisamente en la primacía de la racionalidad - aun cuando esta sea comunicativa - para la toma de decisiones en el escenario político, en tanto que desconoce su dimensión afectiva. En consecuencia, todo lo que viene del instinto, de las pasiones o de los afectos, es rechazado por su carácter no racional. Las lealtades a las instituciones democráticas no están justificadas racionalmente, sino sustentadas en formas de vida de los ciudadanos, en su individualidad y subjetividad.

Al resaltar la racionalidad, se desplaza un elemento primordial: "el papel crucial que desempeñan las pasiones y los afectos en la consecución de la lealtad a los valores democráticos" (Mouffe 2000, p. 109). De este modo, es poco usual que en el Zeitgeist político actual se hable de pasiones. Entonces, ¿por qué no pensar, como propone Mouffe (2011), en un espacio público vibrante, en el que las personas puedan expresar su dimensión afectiva de modo pasional? Así, 
resulta necesario pensar en un modelo político que visibilice la relación entre lo pasional y lo racional, sus diferencias y convergencias. Esto es, una jerarquía que supere el total imperio de lo racional y el total imperio de lo irracional.

Este modelo político debe tener entre sus líneas de acción la politización no solo del espacio público, sino de las distintas esferas sociales y culturales. De esta manera, "politizar significa identificar relaciones de poder e imaginar formas prácticas de transformarlas en relaciones de autoridad compartida" (De Sousa, 2012, p. 332). Así, politizar implica no solo reconocer el carácter político de las distintas esferas sociales, sino descubrir la manera en la que se configura lo político; en ese sentido, es de vital importancia el reconocimiento de las pasiones y de aquello que resulta inaprensible de las relaciones humanas. El modelo se construye a partir de relaciones multipolares, en contraposición a la hegemonía de un único centro de poder. Esto implica la superación de una única lectura del mundo y la apertura hacia nuevas formas de conocer y construir verdad. Para ello, es necesario cultivar las condiciones afectivas, de modo que se configuren nuevas ciudadanías, pues no es posible que se produzca la politización, sin unos agentes concretos ejerciendo su poder.

La resignificación de la política implica pensar dicha posibilidad. Así entonces, en el presente artículo intentamos establecer cómo se configuran las relaciones de poder alrededor de la formación de identidades en la democracia multipolar, relaciones de poder que, como postulamos, son mediadas discursivamente, pero sobre todo, producidas pasionalmente. Mouffe nos es de gran ayuda, en tanto ella rescata la dimensión afectiva de la política, reconociendo la irreductibilidad de su carácter conflictual, como lo veremos en lo que sigue.

\section{Dos modelos de democracia}

El punto de partida para la articulación de los modelos es mostrar la comprensión que tienen Mouffe y Habermas de su propio modelo de democracia, además de identificar factores de cohesión entre los integrantes de una comunidad política. También tomamos en cuenta la manera como cada uno entiende ciertos conceptos y sus opuestos, como consenso/disenso, razón/pasión.

\section{Chantal Mouffe: hacia la construcción de un mundo multipolar}

Mouffe concibe una democracia pluralista, constituida a partir de múltiples centros de poder hegemónicos, con posiciones claramente diferenciadas, y que coexisten en el escenario político (Mouffe 2011). Para dar sustento a su propuesta, la autora intenta superar las visiones que niegan la política; así, parte de un modelo agonista que reconoce la ontología del poder (de lo político) y el carácter conflictual de la naturaleza humana. Mouffe dice: 
[...] concibo "lo político" como la dimensión de antagonismo que considero constitutiva de las sociedades humanas, mientras que entiendo a "la política" como el conjunto de prácticas e instituciones a través de las cuales se crea un determinado orden, organizando la coexistencia humana en el contexto de la conflictividad derivada de lo político. (Mouffe, 2011, p. 16)

Lo anterior define el agonismo, término acuñado por Mouffe (1993, 2011), que implica una transformación de la relación nosotros/ellos, que ya no es vista bajo la mirada antagónica amigo/enemigo, sino bajo el modo adversarial. Este término lo toma del teórico alemán Carl Schmitt, bajo un enfoque en el que la oposición entre contrarios caracteriza la política, además de ser la base de la formación de identidades colectivas. De acuerdo con Mouffe, "la creación de una identidad implica el establecimiento de una diferencia, construida a menudo sobre la base de una jerarquía" (2011, p. 22). Por lo tanto, la democracia pluralista parte de reconocer al contrario como adversario, es decir, como un oponente legítimo, y no negándolo o aduciendo razones morales para su eliminación. Tal construcción no pretende la negociación de conflictos para alcanzar un consenso racional y totalmente inclusivo, pues "la especificidad de la política democrática no es la superación de la oposición nosotros/ellos, sino el modo diferente en que ella se establece" (p. 20).

El reconocimiento de la irreductibilidad del conflicto la lleva a plantear que no puede existir un consenso pleno, universal y racional, pues todo consenso implica formas de exclusión. Lo político es pues antagonista y conflictivo, es una esfera de decisión, de transformación y no una de deliberación. Aceptar que el conflicto puede ser eliminado conduce a relaciones antagónicas, que se expresan en otras formas de identidad colectiva, religiosa, étnica, en ocasiones con rasgos fundamentalistas, que podrían ir en contravía de los principios democráticos (2000).

En una sociedad liberal democrática el consenso es, y será siempre, la expresión de una hegemonía y la cristalización de unas relaciones de poder. La frontera que dicho consenso establece entre lo que es legítimo y no lo es, es de naturaleza política, y por esta razón debería conservar su carácter discutible. (p. 64)

En consecuencia, no puede existir un consenso absoluto, ya que aceptar su posibilidad implica negar la existencia de la pluralidad, la existencia del otro, de lo que Mouffe, apoyándose en Jacques Derrida, llama un "exterior constitutivo". El otro no es simplemente un no-yo, el exterior no puede ser medido o captado en su totalidad por el interior, y es imprescindible para su nacimiento. No es pues una simple negación dialéctica, lo otro no está solamente ahí afuera, sino que pone en jaque la propia existencia, la configura; sin embargo, no basta con decir que no existe un nosotros sin un ellos, sino que lo ajeno es inaprensible, es un no-yo radical y absolutamente desconocido: "el 'ellos' no es el opuesto constitutivo de un 'nosotros' concreto, sino el símbolo de aquello que hace 
imposible cualquier 'nosotros'”' (p. 29). Este es el tinte político que toman las relaciones al antagonizarse, dejan de ser percibidas como simples opuestos y salen a luz la complejidad y la necesidad de las diferencias. Así, dado que solo existe el nosotros/ellos, es necesario para Mouffe evitar que el antagonismo emerja en toda su potencia. Las identidades colectivas deben deslizarse desde lo antagónico, donde se quiere eliminar al otro, hasta lo agónico, donde se reconoce al otro como un adversario. Así, estas identidades se exteriorizan como relaciones de poder, en las cuales quien impone su hegemonía no se persuade de renunciar a ejercer el poder.

Este reconocimiento de la necesidad de la existencia de otro, es decir, el reconocimiento del pluralismo, es para Mouffe lo que define la democracia moderna; sin embargo, la autora no se adscribe al pluralismo absoluto, entendido como "todo vale". Para ella es imposible negar las relaciones de subordinación, pues se cae en la ilusión liberal de un antagonismo sin pluralidad. De esta forma, reconocer el pluralismo implica la necesidad de criticar el objetivismo y el esencialismo, dado que las cosas no existen en sí, sino que el mundo se constituye mediante actos de poder. Toda construcción social objetiva debe identificarse como política, es decir, como el resultado de un acto de subordinación, de exclusión, de lo denominado "exterior constitutivo" (a este entramado entre objetividad y poder Mouffe le da el nombre de "hegemonía"). "Debido a que todo lleva escrito en su propio ser algo distinto de sí mismo y a que, en consecuencia, todo se construye como diferencia, su ser no pude concebirse como pura "presencia" u "objetividad" (p. 38). En el "interior del interior", de este modo, está el exterior constituyéndolo; el poder, en el mismo sentido, no es algo externo, sino propio de las identidades colectivas. Esto quiere decir que el pluralismo se dinamiza constantemente por la lucha entre múltiples polos de poder.

En consecuencia, la democracia pluralista se concreta en una arquitectura multipolar, donde cada polo representa con respecto a otros una ideología claramente diferenciada y jerárquica, que moviliza a los individuos a establecer identidades colectivas, no tanto movidas por la racionalidad, sino por las pasiones (2011). En el escenario de la política, la competencia que pone en tela de juicio la "configuración misma de las relaciones de poder en torno a las cuales se estructura una determinada sociedad: es una lucha entre proyectos hegemónicos que nunca pueden reconciliarse de un modo racional" (p. 28).

Es así que los epígrafes aluden a la necesidad de superar la contemplación e intervenir en las luchas por transformar los modos y las estructuras de poder dominante. Lo que impulsa estos cambios son los afectos, las pasiones, la melancolía y la impotencia, que se torna en fuerza de cambio. Al reconocer el sufrimiento del otro, que se condensa en un clamor colectivo, y con la sabiduría construida comunitariamente, nos damos a la tarea de hacer el mundo más humano, más colorido, menos gris. Es la re-politización de las pasiones, que actúa representacionalmente y configura el espectro democrático. Las identidades, de esta manera, se construyen con "vínculos afectivos"; es el goce de pertenecer. Por eso, Mouffe (2011) refiere la necesidad de construir identidades colectivas, como 
lugares de socialización y edificación personal al interior del espacio público. Lo político no vincula por medio del discurso, sino mediante la resonancia de experiencias, fantasías y deseos que cimienten la visión de futuro; a través de la construcción de fuentes que nos acerquen como humanos, "pues no tenemos el poder de eliminar los conflictos y escapar a nuestra condición humana, pero sí tenemos el poder de crear las prácticas, discursos e instituciones que permitan que esos conflictos adopten una forma más agónica" (p. 138).

Así, Mouffe se opone a modelos de carácter cosmopolita, que pretenden poner fin a un mundo con un único centro de poder y a todos los conflictos, esto es, a la imposición de "una estructura trasnacional de acción política, una comunidad de todas las comunidades democráticas" (p. 106). La defensa del proyecto democrático impone la necesidad de superar el optimismo de un mundo más allá del poder, la soberanía y la hegemonía. Para Mouffe, la visión pospolítica, que se muestra optimista frente a la imposición de la globalización y la democracia liberal, $^{2}$ es la causa de la mayoría de los problemas a los que se enfrenta la democracia. Si se deja atrás la falaz idea de un mundo totalmente reconciliado, se abrirá paso el reconocimiento de su pluralidad. La autora se niega a mostrarse conforme con el supuesto triunfo del individualismo y el progreso de la racionalidad como posibilidad de superar las pasiones y las identidades colectivas. El interés de la propuesta se enfoca en determinar el impacto que han tenido las ideas liberales sobre las ciencias humanas y la política: "mi objetivo es señalar la deficiencia central del liberalismo en el campo político: su negación del carácter no erradicable del antagonismo" (p. 17).

Mouffe aclara que su pluralismo se diferencia del pluralismo liberal; el pluralismo de la democracia liberal unifica la idea de buena vida y la libertad individual, articulando sus principios ético-políticos en instituciones e imponiéndolos al resto de la humanidad. Por eso el pluralismo agonista se opone a la imposición de un único modelo basado en la idea de una racionalidad y moralidad superiores. Ahora bien, Mouffe no plantea un pluralismo sin fronteras, sino que las fronteras no son establecidas en términos antagonistas morales, sino ético políticos. Las demandas excluidas serán aquellas que puedan socavar "las instituciones constitutivas de la asociación política democrática" (p. 129). La naturaleza de dichas instituciones habrá de discutirse, pero para ello es necesaria la existencia de un espacio simbólico compartido. Reconocer la pluralidad implica a su vez cuestionar la idea de un único centro de poder, cuestionar la idea misma de Occidente y la hegemonía del neoliberalismo.

$\mathrm{Al}$ abrirse a la pluralidad de propuestas, Mouffe plantea la necesidad de un "consenso conflictual", el cual se establezca a partir de los valores éticos de libertad e igualdad, aunque la interpretación de estos y su modo de aplicación pueden

2 Para Mouffe, el enfoque racionalista impide una comprensión de la democracia liberal como un espacio paradójico, pues en su afán de eliminar todas las tensiones, dicho enfoque no reconoce la paradoja entre la igualdad, defendida por la democracia, y la libertad individual, defendida por el liberalismo. Para la autora dicha tensión debe concebirse en términos de contaminación, pues en su articulación cada uno afecta la configuración de la identidad del otro. En la vida colectiva, las identidades colectivas responden a un proceso de configuración que, lejos de ser simple, responde a diferentes lógicas constitutivas. 
siempre diferir. En suma, lo legitimo e ilegitimo se constituye en espacios ético políticos contextuales y no morales, ni racionales universales. Dichos principios ético políticos necesitan ser reconocidos por todos y establecidos en una constitución con su respectivo marco legal, es decir, no podía haber un pluralismo legal. La creencia en la posibilidad de que haya un consenso racional que dé fin a todos los conflictos desvía el camino de la democracia, pues convierte en unívoco el pensamiento político y trae como consecuencia la toma de decisiones globalizantes. Por esta razón, la autora se opone a la democracia deliberativa de Habermas, pues esta intenta negar la irreductibilidad del conflicto, apostándole a que es "posible crear en el campo de la política un consenso moral racional mediante la libre discusión" (p. 20).

\section{El modelo político deliberativo de Jürrgen Habermas}

Para hacer una presentación del modelo de democracia deliberativa de Habermas es necesario referirse a los libros Teoría de la acción comunicativa o La ética del discurso, entre otros. El modelo se fundamenta en acciones comunicativas apoyadas en razones logradas por medio de un procedimiento de deliberación racional entre participantes (Habermas, 2010). La deliberación consiste en implementar un proceso de comunicación orientado al entendimiento, definido como "un acuerdo racionalmente motivado por participantes, que se mide por pretensiones de validez susceptibles de crítica" (2002, p. 110). La crítica consiste en que frente a un acto de habla emitido, el oyente debe tomar una postura con un "sí" o con un "no". La racionalidad radica en que el oyente, al tomar una posición crítica, afirma Habermas (2000), con una aceptación o negación, debe aducir buenas razones. Estas razones hacen parte de una argumentación, que busca alcanzar un consenso obtenido mediante el reconocimiento intersubjetivo de todos los participantes del mejor argumento.

En este punto es importante explicar la manera como se ponen en marcha las pretensiones de validez. Para Habermas, los participantes en una práctica discursiva producen emisiones que corresponden a tres relaciones del hablante con el mundo: el mundo objetivo, el mundo subjetivo y el mundo social. El mundo objetivo remite a las acciones teleológicas, el mundo social involucra las relaciones interpersonales y el mundo subjetivo, las vivencias individuales y las emociones. Cada uno de los actos de habla se valida con pretensiones acordes a la relación del hablante con el mundo. El mundo objetivo se valida con lo que Habermas llama "verdad proposicional", que mide la escogencia de los medios para obtener un fin; la corrección normativa corresponde a la pretensión de validez del mundo social y se valida en relación con las normas morales establecidas por consenso; y el mundo subjetivo o dramatúrgico involucra el plano de las emociones, y su pretensión de validez se mide con la congruencia entre el acto de habla del emisor y la autenticidad o la veracidad de sus expresiones subjetivas. Para entrar en este tipo de diálogo, Habermas (2003) asume que los hablantes están

dispuestos, en el momento en el que entran en tal práctica argumentativa, a cumplir con las expectativas de cooperación en la búsqueda 
del tipo de razones que también resulten aceptables para los otros y a dejarse influir y motivar ellos mismos en sus respuestas de "si" y "no" por estas razones, y sólo por éstas. (p. 31)

Sin embargo, Habermas no explica por qué asume como posible que las personas entren en tal práctica dispuestas a cooperar, a abrirse a los argumentos de otros y aceptarlos. En el ámbito de la política, estas prácticas argumentativas posibilitan la formación de la voluntad política mediante acuerdos racionalmente motivados que resultan útiles para coordinar la acción. Con lo anterior en mente, enumeramos los puntos esenciales de la teoría discursiva de Habermas (2010):

1. Las deliberaciones deben hacerse aduciendo buenas razones que son susceptibles de crítica.

2. Las deliberaciones no deben excluir a ningún participante que en principio pueda aportar algo a la discusión o que pueda verse afectado por las acciones que resulten de ella.

3. Las deliberaciones están libres de coerciones tanto externas como internas y solo se ciñen a las reglas procedimentales de argumentación.

4. Las deliberaciones buscan llegar a un acuerdo racionalmente motivado y pueden proseguirse ilimitadamente o retomarse.

Dado que la acción comunicativa está orientada al entendimiento, para Habermas es importante enfatizar en un consenso, que se logra dentro de la dinámica propia del acto comunicativo, en el que es posible encontrar el mejor argumento (2002).

Volviendo al ámbito de la política, Habermas propone un modelo de democracia, como alternativa a aquellos que dominan las discusiones políticas en los Estados Unidos (el republicanismo y el liberalismo). Sin embargo, para construir dicho modelo toma elementos de cada uno. Según Habermas, su modelo democrático $(2002,2010)$ evita el estrechamiento con lo ético del modelo político republicano y con el individualismo utilitarista centrado en la economía de mercado del modelo liberal. Así, en lo que se refiere al republicanismo, Habermas no acoge este modelo por su estrecha confianza en el buen obrar de las personas para la construcción política. Este buen obrar está vinculado con la concepción de vida buena o no fracasada individual, que de hecho es la definición de ética en Habermas. Es en la ética donde reconoce posiciones entre individuos que son irreconciliables y que hacen imposible llegar a un consenso. La complejidad de las sociedades modernas, en las que cada individuo tiene una concepción muy particular de las elecciones que debe realizar para alcanzar su vida no fracasada, explica esta imposibilidad.

Ahora bien, los actos comunicativos de carácter político exigen que los participantes sopesen los actos de habla con algo más que pretensiones de validez 
para llegar a acuerdos racionales que deriven en consenso, y esto nos remite al ámbito de la moral y la justicia. Para Habermas, la justicia es un principio de carácter universal racional ligado a la moral, pues considera que lo justo debe ser lo concertado mediante acuerdos logrados por todos los interesados o afectados. Tomamos la definición de moral de Habermas, entendida como "el conjunto de normas que indican lo que debemos hacer" (2010). La moral tiene un carácter cognitivo $\mathrm{y}$, en consecuencia, racional. Su racionalidad radica en que para su determinación, se procede mediante prácticas discursivas, esto es, la acción comunicativa, de nuevo orientada al entendimiento.

En el caso de la formulación de enunciados morales, el entendimiento se establece en tanto los implicados aceptan las normas por razones de carácter epistémico, mas no orientados por intereses individuales particulares, esto es, éticos. En consecuencia, la ética alude al ámbito de lo privado, mientras que la moral es un universal que incluso trasciende las naciones, como es el caso de los derechos humanos. Habermas (1999, p. 238) escribe: “a diferencia de las cuestiones éticas, las cuestiones relativas a la justicia no guardan relación originariamente con un determinado grupo". La construcción consensual de los enunciados morales sirve para coordinar y orientar - de modo vinculante - la acción social de los miembros; además, permite la resolución de conflictos mediante razones morales reconocidas intersubjetivamente. En efecto, al priorizar el bien común sobre el particular, se entretejen relaciones de carácter solidario entre actores, lo cual implica el reconocimiento mutuo y horizontal entre miembros y desencadena en actos de solidaridad. Mouffe (2005) critica este modelo, porque, según su parecer, solo involucra la dimensión solidaria del ser humano y no la antagónica.

Para Habermas, la pluralidad de visiones y el disenso se presentan en el campo de lo ético. La ética no es un elemento constitutivo de la identidad de una comunidad. De alguna manera, la democracia deliberativa de Habermas acepta la pluralidad de los sujetos privados, pero esta pluralidad debe estar regulada por acuerdos morales, que son aquellos que atañen ya no al ámbito privado, sino al ámbito de lo público. En este sentido, su democracia deliberativa fluctúa entre el liberalismo y el republicanismo.

\section{La articulación de los modelos}

Planteamos un modelo político democrático, cuya estructura arquitectónica corresponde al modelo agonista de Chantal Mouffe, el modelo multipolar explicado anteriormente. En el siguiente apartado precisamos la arquitectura al interior de los polos - en especial preguntándonos acerca de posibles elementos de cohesión-, así como la relación entre ellos y su espacio exterior. Esta arquitectura constituye un esfuerzo por articular los modelos que son el centro de este ensayo. Así, se parte del reconocimiento que hace la autora del "carácter ambivalente de la sociabilidad humana y el hecho de que reciprocidad y la hostilidad no pueden ser disociadas" (Mouffe, 2011, p. 11). Este reconocimiento 
explícito supone entonces que el espacio político debe estar configurado de tal forma que sea posible la sociabilidad, así como su negación. La reciprocidad es entendida aquí como momento de apertura en el que los participantes de una colectividad están dispuestos a ceder posiciones, a escuchar argumentos. La hostilidad se refiere a los momentos de lucha en los que los contendores se cierran ante los otros, pues consideran que sus posturas son irreconciliables, sin dejar de ser agónicas.

\section{Arquitectura al interior de los polos hegemónicos}

Los polos asumidos como centros de poder, de acuerdo con Mouffe $(2011,2000)$, encarnan el carácter pluralista de la democracia. Ahora bien, como primer paso, antes de definir la estructura de los polos, es necesario pensar qué moviliza a la gente a tomar una decisión política para pertenecer a un "nosotros" frente a un "ellos". Siguiendo a Mouffe (2011), asumimos que cuando una persona elige un polo entre los múltiples polos que configuran el espacio político, está movida por la pasión, por lo afectivo, dejando la razón en un segundo plano. Esta dimensión afectiva "entraña el deseo de pertenecer a un grupo[,] lo que es naturalmente constitutivo de los seres humanos" (2010). Para resucitar la política, resulta necesario entonces que la formación de la voluntad política se exprese en la conformación de identidades colectivas dadas por la cercanía afectiva de sus integrantes (2011).

Como segundo paso no lineal, para definir un polo es necesario pensar qué factores, además de la cercanía afectiva, comparten sus miembros. Refiriéndose a Wittgenstein, Mouffe (2000) escribe que "para llegar a un acuerdo en materia de opiniones, ha de haber primero una concordancia sobre las formas de vida". Estas formas determinan a su vez unas prácticas particulares. Así, para nosotros, un polo se define también como un conjunto de personas que comparten formas de vida, visiones de mundo, aunque no necesariamente de manera plena. Esto último es central en la articulación que hacemos de los modelos por dos motivos. Mouffe (2011) reconoce que la sociabilidad y la insociabilidad son formas de lo humano. Laclau y Mouffe (2004) consideran, además, que el espacio público está surcado "por lógicas de equivalencia y de diferencia" (p. 173). ¿Por qué no pensar entonces, asumiendo ciertas precauciones, que dicha equivalencia se expresa al interior de los polos?

Dado que para Mouffe los polos son proyectos políticos, es momento de preguntar: ¿cómo es que los participantes de un polo realizan sus acuerdos programáticos? ¿En qué lugares del espacio político y en qué forma tienen lugar las prácticas discursivas que la filósofa admite también como elemento constitutivo de la arena política? De acuerdo con la autora, la respuesta está en los polos, a pesar de su temporalidad. Resulta natural pensar que al interior de los polos, asumidos como lugares para el discurso, se dieran prácticas comunicativas que involucraran ciertas características o formas de proceder tomadas de la ética discursiva, en mayor o menor grado, con el fin de cumplir con ciertos propósitos. 
No obstante, es importante enfatizar que nos apartamos de la idea de una práctica discursiva que pueda resultar políticamente neutral, racional y simétrica para todos los proyectos políticos dentro de un espacio democrático. Aquí conviene preguntar: ¿qué premisas se podrían mantener?, ¿cuáles resultarían incompatibles con una democracia agonista? Si retomamos las premisas presentadas en el acápite 3.2 y pensamos que los participantes de un polo que quieran discutir o deliberar sobre asuntos capitales están dispuestos a aducir buenas razones, como propone Habermas, también es de esperar que estas razones puedan ser criticadas, y que en ellas participen todos aquellos que puedan resultar afectados por los acuerdos que resulten de tales discusiones.

Al respecto, Laclau y Mouffe (2004) señalan que los discursos que se dan al interior de una identidad política son fijaciones parciales que aúnan un cierto carácter cognoscitivo. Ahora, con respecto a la premisa que reza: "las deliberaciones buscan llegar a un acuerdo racionalmente motivado y pueden proseguirse ilimitadamente o retomarse", Habermas $(1998,2001)$ asume que para que la ética discursiva discurra sin tropiezos, resulta necesario que los miembros estén dispuestos a cooperar y a llegar a acuerdos consensuales. Si bien estos principios pueden ser compatibles con el modelo agonista, nos apartamos de Habermas en su pretensión de que dichos discursos aspiren a acuerdos universales.

Justamente, los polos asumidos como regiones discursivas excluyen al resto de hegemonías que configuran el espacio político. Siguiendo a Mouffe (2011), consideramos que no siempre las personas están dispuestas a entrar en prácticas discursivas que finalicen en consenso. En suma, dado que los polos implican un grado importante de cercanía afectiva y de formas de vida compartidas, es de esperar que las personas establezcan prácticas discursivas a la manera habermasiana, sea con la intención de llegar a acuerdos, sea con el propósito de que no exista coerción de los participantes en la práctica argumentativa.

A este respecto, cabe decir que la pertenencia a un polo, asumido como identidad colectiva, implica que un grupo de personas esté allí, porque tiene un influjo "real en los deseos y fantasías de la gente" (p. 13). Más adelante, en su libro En torno a lo político, Mouffe agrega, pensando en que los participantes son votantes, que estos deberían "tener la posibilidad de identificarse con una gama diferenciada de identidades políticas democráticas" (p. 76).

Si entendemos cada polo con un proyecto político distinto, un polo particular, al menos temporalmente, está constituido por participantes que comparten dicho proyecto. Aunque hay diferencias entre los integrantes, estas no están claramente diferenciadas, lo cual es condición de posibilidad para dicho proyecto. Así, la reciprocidad que Mouffe reconoce también como elemento constitutivo de la democracia resulta factible como posible práctica al interior de los polos. Es allí, y bajo las anteriores condiciones, donde los miembros de una colectividad podrían estar dispuestos a establecer "relaciones simétricas [...] en la comunicación, de reconocimiento mutuo, de asunción de la perspectiva del otro" (2000, p. 166). 
En suma, esta articulación hace explícito que el modelo multipolar de Mouffe necesita como posible práctica al interior de los polos la acción comunicativa de Habermas, orientada al entendimiento. La cercanía afectiva y una visión de mundo compartida son necesarias para que las personas estén dispuestas a cooperar, a no ejercer coerción sobre otros, a ser solidarios como bien quiere Habermas.

No obstante, conviene considerar una crítica que hace la filósofa Iris Marion Young a Habermas. Young (1996) afirma que en una conversación las relaciones no necesariamente son simétricas, pues las personas tienen formas alternas de actuar comunicativamente, como en el caso de los gestos. Es posible que una distancia grande entre formas de vida implique en una conversación que unas personas hablen o que se acompañen sus actos de habla con gestos. Un diálogo simétrico genuino no sería factible en estas circunstancias.

Así, la cercanía emotiva y la visión de mundo compartida hacen posible que aun cuando el diálogo sea asimétrico en algún sentido, resulte más fácil entenderse y sea posible establecer acuerdos consensuales. Volviendo a Wittgenstein, las prácticas discursivas orientadas al consenso deben incluirse como una práctica, entre muchas otras, pues posibilitan que los participantes de la colectividad estén en consonancia. Los acuerdos logrados implican la planeación estratégica que permite la coordinación de acciones para no desaparecer como fuerza. Pero además, la búsqueda del poder comunicativo (Habermas, 2010) basado en teorías discursivas implica el mantenimiento de lazos sociales, orientando de forma eficaz las acciones comunes. Lo político requiere en ciertos momentos de pactos en el plano de la razón. Es deseable que los miembros formen un frente común y que las posiciones de cada uno se vayan movilizando paso a paso, pues para Habermas, en una deliberación todo argumento es susceptible de crítica, lo que en momentos de apertura de los participantes permite la construcción de acuerdos robustos que orientan la práctica política. Pero, ¿en qué terreno deben darse los acuerdos?

La apuesta por la democracia de este modelo implica hacer visible factores que nosotros consideramos son de cohesión. Además de la dimensión afectiva, ¿qué en el campo de lo moral o de lo ético es lo que permite que se dé cierto grado de cohesión entre los miembros de un polo? Tanto en Habermas como en Mouffe, la formación de la voluntad política es un factor de cohesión. Esta voluntad tiene en Habermas (1999) carácter racional, pues hay intereses y valores que tienen validez general, más allá de los límites de una comunidad jurídica concreta, que deberían ser construidos intersubjetivamente, entre ellos la justicia, considerada como una base común universal. Sin embargo, nos resulta problemático asumir que pueda existir una moral universal. Cada polo debería poder definir sus reglas morales.

En efecto, como las visiones de mundo entre polos son irreconciliables en un momento particular, es difícil que pueda existir una idea de justicia que aplique a todos los polos; sin embargo, Mouffe plantea que son necesarias unas 
normas jurídicas comunes. Ahora, que no haya una interpretación de justicia, de igualdad o de libertad univoca, no contradice el que los integrantes de un polo tengan momentos discursivos de tipo habermasiano, para establecer acuerdos morales e incluso estrechar lazos de carácter empático. Estos momentos de tipo comunicativo actúan a la vez fortaleciendo la identidad de los polos y como formación de una trinchera hacia el exterior.

\section{Las fronteras políticas, el borde de los polos}

Hablar de construcción de identidad dentro de una esfera hegemónica implica preguntarse acerca de los límites o fronteras políticas desde dos dimensiones distintas. Por una parte, las fronteras entre polos dan a sus integrantes un sentimiento de unidad afectivo que también puede ser de carácter político-jurídico, económico, cultural y social. Por otra parte, un modelo como el que proponemos - que reconoce tanto el carácter asociativo como disociativo de las relaciones humanas - supone que las fronteras políticas entre polos están bien demarcadas, pues permiten la distinción nosotros/ellos, separando visiones de mundo claramente diferenciadas, de acuerdo con Mouffe $(2000,2011)$. Sin embargo, dentro de un enfoque agonista, estas fronteras no pueden ser absolutamente excluyentes, pues se ha de aceptar al otro como un adversario legítimo, perteneciente a la humanidad en su conjunto. Ahora, desde un enfoque deliberativo, las fronteras, siendo movibles, delimitan en un momento particular una región discursiva con prácticas compartidas, permitiendo el reconocimiento solidario.

No obstante, esto no significa que las fronteras no puedan redefinirse de manera dinámica por la contingencia del espacio público. Por ejemplo, cuando una colectividad al interior de un polo amplía sus convicciones, al punto de tornarse cercana a la de otro polo, puede ocurrir que dos o varios polos se unifiquen. Para ilustrar lo anterior, podemos considerar las luchas de los homosexuales en los Estados Unidos, que en ocasiones se han unido con movimientos sociales feministas. Podemos suponer también que al interior de un polo se conformen subconjuntos de personas cuyas visiones de mundo se tornen lejanas a las que orientan el polo, de tal modo que ya no sea posible lograr acuerdos consensuales. Como consecuencia, puede ocurrir que un polo se subdivida y se reestructure, conformando dos o más nuevos polos. Este es el caso de la segunda ola feminista que surge en Europa y en los Estados Unidos en la década de los sesenta. En su lucha en contra del androcentrismo, las feministas se enfrentaron al dilema de no poder incluir sus reivindicaciones en los colectivos a los que pertenecían, pues no tomaban en cuenta injusticias asociadas con el género. Fraser (2014) refiere el caso de las feministas que también pertenecían a la izquierda:

Para las feministas liberales y radicales, esto no suponía un problema excesivo, simplemente podían separarse y abandonar la izquierda. Para las feministas socialistas y las anti-imperialistas tenían que optar por afrontar el sexismo dentro de la izquierda y seguir formando parte de ella. (p. 18) 
Los anteriores ejemplos ilustran que las fronteras políticas de este modelo, si bien están bien demarcadas, a su vez son dinámicas, movibles y contingentes. Además de separar los polos deben separar también a los individuos que ponen en peligro las instituciones democráticas, como propone Mouffe (2011).

\section{La relación entre polos}

Siguiendo a Schmitt, de quien Mouffe parte, asumimos que los seres humanos tienden a agruparse en divisiones que son disociativas. Para Schmitt (1991), el carácter amigo/enemigo no se refiere a motivos privados de discordia ni a una distinción de carácter puramente espiritual o normativa entre individuos. En particular, solo es enemigo el enemigo público, esto es, el conjunto de personas que se opone combativamente a otro conjunto análogo. Combativamente no quiere decir que participantes de diferentes polos deban ser enemigos o establecer una relación violenta, pero sí que sus ideas y convicciones, al menos en cierto momento, resulten irreconciliables. Así, la relación entre polos es de carácter adversarial, se distingue un "nosotros" a partir de un "ellos", lo que posibilita a los sujetos políticos movilizarse política y, en consecuencia, afectivamente (Mouffe 2011). La siguiente cita elucida la relación que se da entre polos.

Tal adversario no puede ser definido [...] sino en términos de puntos nodales de poder que necesitan ser puestos como objetivos y transformados con el fin de crear las condiciones de una nueva hegemonía. Se trata de una "guerra de posiciones" (Gramsci) que necesita ser lanzada en una multiplicidad de lugares. (Mouffe, 2010)

Si la colectividad no tiene argumentos sólidos, "puntos nodales", entonces ese polo podría poner en peligro su existencia en el espacio público. Ahora, ¿de qué manera puede una identidad colectiva definir los objetivos y los puntos nodales de su proyecto, si no es por medio de una acción comunicativa de carácter intersubjetivo entre sus miembros? En el subtítulo sobre la arquitectura al interior de los polos, argumentamos que la teoría discursiva de Habermas resulta una posible práctica que podría emerger de modo natural, dada la cercanía en cuanto a las visiones de mundo. El acoger ciertas premisas podría facilitar emprender acciones conjuntas, y así alcanzar la solidez en las ideas y propuestas. También, abrirse a los argumentos de los demás y establecer acuerdos, aun cuando temporales, puede favorecer una lucha estructurada frente a otros polos.

Por su parte, Habermas (2001b) es un contradictor del modelo multipolar, pues de acuerdo con él, la modernidad impone sobre todas las culturas y las comunidades una dinámica irremediable, en la que para sobrevivir, para no desaparecer, subsumidas por la economía, deben abrirse. Refiriéndose a las comunidades, Habermas afirma que el "blindaje autártico, ya no es posible en la actual situación mundial". "El mismo conflicto de las culturas es hoy el lugar en el marco de una sociedad mundial en la cual, los actores colectivos, a pesar de las diferentes tradiciones culturales, quieran o no, deben ponerse de acuerdo con respecto a las normas de su común convivencia". Mouffe no 
pretende que en su modelo los polos deban estar blindados. Para la filósofa, la democracia consiste en mantener "la lucha entre proyectos hegemónicos opuestos que nunca pueden reconciliarse de un modo racional" (2011, p. 28). Esta última cita ilustra en gran medida la relación que se da entre los polos en el modelo. Al igual que Mouffe, en esta relación reconocemos el carácter conflictual de la política y, en consecuencia, el de los humanos. Para ella, a diferencia de Habermas, es necesario reconocer la existencia de posiciones irreconciliables, de posturas antagónicas, pues el fin de la democracia se produce al postular un consenso absoluto.

Tenemos que la asociación política o espacio público, para retomar el vocabulario de Mouffe, requiere de posiciones no antagónicas, que ella también reconoce y que, según Habermas, garantizan los lazos sociales, pues también es necesario que las personas tengan vías para expresar su naturaleza racional/pasional, esto es, antagónica/consensual, y escoger el polo con la ideología cercana a su afectividad. También Mouffe señala que la lucha por el poder debe darse en "multiplicidad de lugares", que nosotros interpretamos como aquella referida a los demás polos hegemónicos.

\section{El exterior de los polos}

Si planteamos que nuestro modelo no es un modelo universalista, es necesario reconocer la existencia de formas alternativas a la misma democracia; sin embargo, el reconocer al otro como perteneciente a una misma humanidad, pero diferente en cuanto a sus prácticas y pensamientos, tal vez sea el camino para una existencia agonista legítima. En este sentido, el reconocimiento del conflicto como inherente a toda relación social lleva a que sea necesario pensar y conformar sistemas de comunicación que permitan transfigurar las diferencias y los conflictos. Es cuestión de aprender a vivir en un dinamismo inacabado, el cual se escapa a las tradicionales ideas de orden social.

En todo caso, es usual que la mayoría de los seres humanos tiendan a conformar colectividades de manera gregaria. Podría pensarse que responden a sus pasiones, pero esto no puede darse por supuesto, así que resulta necesario ahondar en la manera en cómo las pasiones configuran verdaderamente las identidades colectivas. Fuera de ellas, existen individuos que marcan la diferencia, ya sea porque deciden no pertenecer a ningún polo, o porque son aislados, por no responder a las normatividades sociales. Pero es evidente que el modelo que aquí proponemos busca una salida a las conflictividades colectivas, que aunque tienen en cuenta al individuo, lo ven como un sujeto colectivo y no como un individuo aislado. El camino de la soledad es recorrido por unos pocos.

\section{La totalidad del espacio democrático}

En los polos entendidos como totalidad, se dan relaciones de reciprocidad, pues aunque mantienen relaciones adversariales y discrepancias en cuanto a 
las interpretaciones sobre la libertad y la igualdad, "comparten lealtad hacia los principios liberales democráticos" y hacia las instituciones que los resguardan. De esta manera, la democracia implica la construcción de un demos común, y el pertenecer a este garantiza la posesión de determinados derechos. Existe aquí cierta homogeneidad que sustenta las bases de la igualdad en la democracia. "La lógica de la democracia implica por tanto un momento de cierre requerido por el propio proceso de constitución del 'pueblo'"' (Mouffe, 2000, p. 59). Este cierre se concreta en tanto los individuos son ciudadanos, y no solo por pertenecer a una abstracción llamada humanidad. Mouffe muestra cómo el término pueblo, que Schmitt plantea en contraposición al de humanidad de los liberales, es tan necesario como este último. El pueblo, como lugar concreto de prácticas políticas, hace frente al universalismo abstracto, pero la referencia a la "humanidad" y a los derechos humanos universales ayuda a identificar las formas de exclusión de esas mismas prácticas políticas. En consonancia, es posible afirmar, dentro de la lógica mouffeana, que algunos elementos de Habermas pueden hacer parte de las dinámicas polares, claro está, matizados o como contraparte necesaria.

\section{Conclusiones}

Construir un modelo político que responda a una configuración multipolar requiere reconocer que la política y, en general, la organización social se sustenten en la ontología del poder. Es necesaria también una nueva comprensión del poder y la democracia, pues aquel no debe ser entendido como un absoluto trascendental, sino que su posibilidad de desarrollo se da en el ámbito concreto de la intersubjetividad. En "la capacidad de recibir poder, sufrir influencias, cambiar y ser cambiado" (Woldin, año), no nos contentamos con contemplar los entramados de poder, sino que nuestra experiencia nos mueve a participar activamente en ellos. Así,

el concepto de democracia no se puede fundamentar en alguna noción ahistórica y trascendente de la verdad y la autoridad. La democracia es un "lugar" de lucha, y como práctica social adquiere forma propia mediante los conceptos ideológicos de poder, política y comunidad, que se hallan en competencia entre sí. (Giroux 1993, p. 54)

Se clarifica entonces la importancia de construir identidades colectivas, pues reconocer la intersubjetividad mediada por el lenguaje, como el suelo necesario sobre el que se desenvuelven las relaciones humanas, permite encontrar un posible camino para construir un enfoque agonista, es decir, un enfoque en el que se reconozca la existencia del otro como un adversario legítimo. Así, con esta doble ontología del poder e intersubjetividad, es posible dirigir la mirada a la construcción de identidades en el espacio público, plantear alternativas políticas a la crisis de la democracia, vivificar y re-politizar la política, en tanto escenario de construcción y lucha social. 
Estas alternativas deben reconocer que la construcción de proyectos políticos requiere tanto de la pasión como de la razón, sin caer en dualismos o dialécticas reduccionistas. ¿Por qué pensar que la voluntad política solo puede crearse en un registro racional y no puede moverse también por pasiones y afectos? Aceptando la naturaleza ambivalente de los seres humanos, creemos que el escenario político debe estar constituido de tal forma que esta naturaleza dual se exprese. Esto implica precisamente que nos reconozcamos como pertenecientes a una misma humanidad, habitantes de un mismo planeta y responsables de él, de nosotros y de los otros.

Una ética del cuidado basada en la solidaridad y lo pasional-conflictual puede ayudar en las construcciones colectivas. Por lo tanto, la construcción de las identidades colectivas implica la defensa de un espacio público vibrante, en el que existan posibilidades de desarrollo del pensamiento político. Sin embargo, la política debe ser dinámica, el mundo actual exige que no haya esencialismos, la validez debe ser considerada momento a momento. Esta dinámica sugiere —además de una idea de democracia como terreno de lucha y solidaridad entre personas- que los sujetos sean democráticos frente a sí mismos, que se reconozcan en su dimensión cognitiva y afectiva. La anterior arquitectura democrática es casi más plural que la de Mouffe y más solidaria que la de Habermas, pues los reconcilia, pero subraya también sus diferencias de manera democrática.

Nos preguntamos entonces: ¿cuál sería, al menos utópicamente, la condición de posibilidad de un tal modelo que busca que la pasión se metamorfosee en un antagonismo agónico y no desemboque en sectarismos dogmáticos? Y si el problema de la democracia no son sus ideales, sino el que no se hayan puesto en práctica, ¿cómo y dónde hacer posible su desarrollo? En parte, la respuesta a estos interrogantes está en la educación. Por esta razón, es necesario plantear la necesidad de construir en las esferas públicas educativas escenarios de alfabetización política, espacios de construcción de ciudadanías críticas. Esto puede lograrse, según plantea Giroux (1993), haciendo lo político más pedagógico y lo pedagógico más político, lo cual es una manera que muestra la necesidad de ligar la lucha política que se desarrolla en los espacios educativos con el contexto social.

De este modo, potenciando la acción y el pensamiento político se fortalece la democracia, la cual se valida como espacio de poder, de lucha y de construcción de comunidades diferenciadas. La formación de sujetos políticamente críticos y creadores es la base para una transformación cultural y la construcción de una verdadera democracia, pues no puede haber democracia si los ciudadanos están sumergidos en el analfabetismo político e hipnotizado por un centro de poder hegemónico, que se disfraza bajo su ropaje mesiánico y su discurso sectario. La deliberación es tan solo una herramienta de reconocimiento de la conflictividad constituyente de los seres humanos y de la política.

Para cerrar de una buena manera este artículo, retomamos una idea de Rorty pensando en Hume, cuando defiende que debemos tender a un progreso de los sentimientos que supere las antiguas dicotomías, para realizar de mejor manera nuestros proyectos en común (2000). 


\section{Referencias}

Arte Nuevo: derechos, noticias, observatorio. (2010). La democracia tiene que darles lugar al disenso y a la pasión. Entrevista con Chantal Mouffe. En La Nación.

Benhahib, S. (1996). Democracy and difference: Contesting the boundaries of the political. United Kingdom: Princeton University Press.

De Sousa, B. (2012). De la mano de Alicia: lo social y lo político en la postmodernidad. Bogotá: Siglo del Hombre.

Fraser, N. (2008). Escalas de justicia. Barcelona: Herder.

Fraser, N. (2009). El feminismo, el capitalismo y la astucia de la historia. Recuperado de http://newleftreview.es/authors/nancy

Giroux, H. (1993). La escuela y la lucha por la ciudadanía. Pedagogía crítica en la época moderna. México: Siglo Veintiuno.

Habermas, J. (1998). Facticidad y validez. Frankfurt: Trotta.

Habermas, J. (2001a). Teoría de la acción comunicativa. Madrid: Taurus.

Habermas, J. (2001b). La constelación postnacional. Madrid: Paidós.

Habermas, J. (2003). La ética del discurso y la cuestión de la verdad. Estudios de teoría política. Buenos Aires: Paidós.

Horkheimer, M. (2010). Critica de la razón instrumental. Nueva York: Trotta.

Laclau, E. y Mouffe, C. (2004). Hegemonía y estrategia socialista. Hacia una radicalización de la democracia. Argentina: Fondo de Cultura Económica.

Márquez, A. y Díaz, Z. (2006). Crítica a la razón instrumental de las instituciones políticas de la modernidad. Maracaibo: Universidad de Zulia.

Merleau-Ponty, M. (1985). Fenomenología de la Percepción. Barcelona: Planeta Agostini.

Mouffe, C. (1993). El retorno a lo político. Barcelona: Paidós.

Mouffe, C. (2000). La paradoja democrática. Barcelona: Gedisa.

Mouffe, C. (2011). En torno a lo político. Buenos Aires: Fondo de Cultura Económica.

Nietzsche, F. (2000). El nacimiento de la tragedia. Madrid: Alianza. 
Rorty, R. (2000). Respuesta a Jürgen Habermas. Buenos Aires: Amorrortu.

Schmitt, C. (1991). El concepto de lo político. Madrid: Alianza.

Young, M. (1996). S. d. 